\title{
KANDUNGAN SIKLAMAT PADA MINUMAN ES CENDOL
}

\author{
Geminsah Putra H Siregar \\ Politeknik kesehatan Kemenkes Medan \\ Email :geminputrasiregar@gmail.com
}

\begin{abstract}
Cyclamate is an artificial sweetener that is often added to drinks and food. In trade, cyclamate is known by the trade names assugrin, sucaryl, sucrose or sarimanis. The negative effects caused by sodium cyclamate are not immediate, it may have to wait two or thirty years later. The effects include increasing the potential for obesity, dental disorders, learning disorders, emotions, and mental health. testicular wasting and chromosomal damage. The purpose of this study was to determine the presence or absence of cyclamate content in cendol ice. The examination was carried out at the Amami Chemistry Laboratory, Health Polytechnic of the Ministry of Health, Medan, Department of Health Analyst using a qualitative test, namely the color test (deposition) with a total sample of 7 samples taken from cendol ice drink traders. Based on the qualitative test results obtained from 7 samples, 4 positive samples contained cyclamate. By knowing the presence of cyclamate content, it is hoped that producers will use food additives that do not have a negative effect on consumer health. Based on the Minister of Health Regulation No. 033/2012 artificial sweeteners are only intended for low-energy products or for people with diabetes mellitus and not for general let alone especially for children.
\end{abstract}

Keywords: Cendol Ice, Cyclamate

\begin{abstract}
ABSTRAK
Siklamat merupakan pemanis buatan yang sering ditambahkan kedalam minuman dan makanan. Dalam perdagangan Siklamat dikenal dengan nama dagang assugrin, sucaryl, sucrose ataupun sarimanis. Efek negatif yang ditimbulkan natrium siklamat tidak secara langsung, mungkin harus menunggu dua atau tiga puluh tahun kemudian. Efek yang ditimbulkan antara lain, meningkatkan potensi obesitas, karies gigi, gangguan belajar, emosi, mental. pengecilan testicular dan kerusakan kromosom. Tujuan penelitian ini yaitu untuk mengetahui ada tidaknya kandung siklamat pada es cendol. Pemeriksaan dilakukan di Laboratorium Kimia Amami Politeknik Kesehatan Kemenkes Medan Jurusan Analis Kesehatan dengan menggunakan uji kualitatif yaitu uji warna (pengendapan) dengan jumlah sampel sebanyak 7 sampel yang diambil dari pedagang minuman es cendol. Berdasarkan hasil uji kualitatif yang diperoleh dari 7 sampel tersebut diperoleh hasil 4 sampel positif mengandung siklamat. Dengan diketahuinya adanya kandungan siklamat tersebut diharapkan kepada produsen agar menggunakan bahan tambahan pangan yang tidak memiliki efek negatif bagi kesehatan konsumen. Berdasarkan Peraturan Menteri Kesehatan Tahun Nomor 033 Tahun 2012 pemanis buatan hanya ditujukan untuk produk rendah energi atau bagi penderita diabetes mellitus dan bukan untuk konsumsi umum apalagi untuk anak - anak.
\end{abstract}

Kata kunci: Es Cendol, Siklamat

\section{PENDAHULUAN}

\section{Latar Belakang}

Keamanan pangan pada suatu produk makanan sangat diperlukan dalam meningkatkan kualitas pangan. Pangan yang tidak aman dapat menyebabkan penyakit yang disebut dengan foodborne diseases, yakni gejala penyakit yang timbul akibat mengkonsumsi pangan yang mengandung bahan atau senyawa beracun atau organisme patogen ${ }^{(1)}$.
Minuman jajanan dipasar tradisional merupakan industri skala kecil yang biasanya kurang memperhatikan sanitasi dan keamanan pangan. Minuman jajanan seperti es cendol, es teler, es kelapa muda dan es sirup yang rasanya enak, manis, segar dan penampilannya yang menarik, menjadikan produk ini banyak disukai oleh masyarakat. Minuman jajanan menjadi salah satu contoh produk yang mencampurkan pemanis buatan. Dalam produk ini, takarannya harus sesuai dengan syarat yang berlaku menurut Standar Nasional Indonesia. Pemanis buatan yang tidak sesuai syarat pemakaian dalam 


\section{Vol. 10 No. 1 Januari - April 2019}

minuman jajanan menjadi salah satu masalah keamanan pangan .

Makanan/minuman jajanan (street food) sudah menjadi bagian yang tidak terpisahkan dari kehidupan masyarakat sehari-hari, baik di perkotaan maupun di pedesaan. Akibat tingginya kebutuhan masyarakat perkotaan terhadap jenis makanan/minuman yang praktis karena banyaknya aktivitas masyarakat mengakibatkan kurang terjaminnya kebutuhan berbagai jenis makanan/minuman dalam jumlah besar. Semua hal tersebut mendorong produksi untuk menggunakan Bahan Tambahan Makanan (BTM) (2).

Penggunaan bahan kimia sebagai salah satu bahan tambahan pada makanan dan minuman saat ini sering ditemui. Bahan tambahan merupakan bahan yang sengaja ditambahkan kedalam makanan dan minuman untuk mendapatkan kualitas yang lebih baik. Bahan tambahan yang dikenal dengan zat adiktif pada makanan atau minuman dapat berupa pewarna, penyedap rasa dan aroma, pemantap, antioksidan, pengawet, pengemulsi, pemucat, pengental dan pemanis ${ }^{(3)}$.

Pemanis merupakan senyawa kimia yang sering ditambahkan dan digunakan untuk keperluan produk olahan pangan, industri serta minuman dan makanan kesehatan. Berdasarkan proses produksi bahan pemanis dapat dibagi menjadi 2 golongan, yaitu pemanis alami dan pemanis buatan (sintetis).

Pemanis alami dapat diperoleh dari tumbuhan, seperti kelapa, tebu, dan aren. Selain itu, pemanis alami dapat pula diperoleh dari buah-buahan dan madu. Pemanis alami berfungsi untuk meningkatkan cita rasa dan aroma manis, memperbaiki siat-sifat fisik, sebagai pengawet, memperbaiki sifat-sifat kimia sekaligus merupakan sumber kalori bagi tubuh ${ }^{(4)}$.

Sedangkan, pemanis buatan (sintetis) merupakan zat yang dapat menimbulkan rasa manis tersebut, sementara kalori yang dihasilkan jauh lebih rendah daripada gula. Pada umumnya pemanis sintetis mempunyai struktur kimia yang berbeda dengan polihidrat gula alam ${ }^{(5)}$.

Jenis pemanis yang digunakan pada sebagian besar makanan/minuman jajanan adalah campuran pemanis sintetis sakarin dan siklamat (2).

Perkembangan

industri minuman/makanan yang menggunakan pemanis buatan semakin berkembang pesat, mengingat bahan tambahan makanan/minuman mempunyai harga yang lebih murah dibandingkan dengan gula alami atau yang sering kita kenal sebagai gula tebu atau gula pasir sehingga dengan demikian akan memperbesar keuntungan pedagang ${ }^{(6)}$.

Siklamat merupakan pemanis buatan yang tidak menghasilkan energi. Siklamat biasa terdapat sebagai garam natrium atau kalsium. Kemanisanya kurang lebih 30 kali lebih manis daripada sukrosa. Di Indonesia penggunaan siklamat masih di izinkan, tetapi sebenarnya hasil metabolisme siklamat yaitu sikloheksamin merupakan senyawa karsinogen ${ }^{(5)}$.

Menurut Peraturan Menteri Kesehatan RI No.033 Tahun 2012, kadar maksimum asam siklamat yang diperbolehkan dalam pangan dan minuman berkalori rendah untuk penderita diabetes mellitus adalah $3 \mathrm{~g} / \mathrm{kg}$ bahan pangan dan minuman (7). Dan menurut World Health Organization (WHO), batas konsumsi harian siklamat yang aman Acceptable Daily Intake $(A D I)$ adalah $11 \mathrm{mg} / \mathrm{kg}$ berat badan ${ }^{(8)}$.

Pada penelitian yang lebih baru dinyatakan bahwa konsumsi siklamat dapat mengakibatkan pengecilan testis (buah pelir) dan kerusakan kromosom ${ }^{(6)}$.

\section{METODE}

\section{Tempat Dan Waktu Penelitian}

Analisa kualitatif natrium siklamat dalam es cendol yang dijual di pasar tembung dilakukan di Laboratorium Kimia Politeknik Kesehatan Kemenkes Medan Jurusan Analis Kesehatan di Jalan Willem Iskandar Pasar V Barat No. 6 Medan Estate. Penelitian ini dilaksanakan pada bulan februari - maret 2019.

\section{Alat}

Tabung reaksi, corong kaca, kertas saring, pinset, pipet skala, karet penghisap, pipet tetes, kertas lakmus, labu ukur, dan centrifuge. 


\section{Bahan}

Barium Chlorida (BaCl2), Asam Chlorida ( $\mathrm{HCl})$, Kalium Nitrit (KNO2) dan Aquades.

\section{Prosedur Penelitian}

Ambil $10 \mathrm{ml}$ sampel cair dengan pipet ukur dan masukkan ke dalam tabung reaksi. Kemudian tambahkan seujung sendok Kristal $\mathrm{BaCl}_{2}$ ke dalam tabung reaksi berisi sampel kemudian dikocok dan dibiarkan selama 5 menit. Setelah itu sampel disentrifuge. Filtrate kemudian dibagi ke dalam dua tabung. Tabung pertama dibiarkan (tidak diberi reagen) dan tabung kedua ditambahakn HCL 10\% (lakmus biru menjadi warna merah). Setelah tabung menjadi asam, ditambahkan seujung sendok kecil Kristal $\mathrm{KNO}_{2}$. Mengamati perubahan yang terjadi pada kedua tabung. Apabila dihasilkan endapan putih berarti terdapat siklamat pada sampel ${ }^{(2)}$.

\section{Analisa Data}

Data yang akan diperoleh dari hasil penelititian di laboratorium akan disajikan dalam bentuk tabel dan dianalisa secara kualitatif.

\section{HASIL}

Dari hasil penelitian yang dilakukan terhadap 7 sampel minuman es cendol diperoleh hasil sebagai berikut :

Tabel 1 Data hasil uji siklamat dengan metode pengendapan terhadap 7 sampel minuman es cendol.

\begin{tabular}{|l|l|l|l|}
$\mathrm{N}$ & SAMPE & UJI & HASIL \\
\hline
\end{tabular}

\begin{tabular}{|c|c|c|c|}
\hline $\mathrm{O}$ & $\mathrm{L}$ & $\begin{array}{c}\text { PENGENDAPA } \\
\mathrm{N}\end{array}$ & \\
\hline 1 & I & $\begin{array}{l}\text { Terjadi Endapan } \\
\text { Putih }\end{array}$ & Positif \\
\hline 2 & II & $\begin{array}{c}\text { Terjadi Endapan } \\
\text { Putih }\end{array}$ & Positif \\
\hline 3 & III & $\begin{array}{c}\text { Terjadi Endapan } \\
\text { Putih }\end{array}$ & Positif \\
\hline 4 & IV & $\begin{array}{l}\text { Tidak Terjadi } \\
\text { Endapan }\end{array}$ & $\begin{array}{l}\text { Negati } \\
\mathrm{f}\end{array}$ \\
\hline 5 & $\mathrm{~V}$ & $\begin{array}{c}\text { Tidak Terjadi } \\
\text { Endapan }\end{array}$ & $\begin{array}{l}\text { Negati } \\
\mathrm{f}\end{array}$ \\
\hline 6 & VI & $\begin{array}{c}\text { Terjadi Endapan } \\
\text { Putih }\end{array}$ & Positif \\
\hline 7 & $\overline{\text { VII }}$ & $\begin{array}{l}\text { Tidak Terjadi } \\
\text { Endapan }\end{array}$ & $\begin{array}{l}\text { Negati } \\
\mathrm{f}\end{array}$ \\
\hline & Blanko & $\begin{array}{l}\text { Tidak Terjadi } \\
\text { Endapan }\end{array}$ & $\underset{f}{\text { Negati }}$ \\
\hline & Standar & $\begin{array}{c}\text { Terjadi Endapan } \\
\text { Putih }\end{array}$ & Positif \\
\hline
\end{tabular}

\section{PEMBAHASAN}

Dari 7 sampel es cendol yang di analisa secara kualitatif diperoleh hasil bahwa 4 sampel es cendol positif mengandung siklamat. Berdasarkan pemeriksaan kualitatif dengan uji pengendapan diperoleh endapan warna putih pada sampel dan tiga sampel es cendol negatif yang tidak mengandung siklamat. Pada sampel es cendol nomor 1, 2, 3 dan 6 terbentuk endapan putih dan pada sampel nomor 4, 5 dan 7 tidak terbentuk endapan putih. Terbentuknya endapan putih pada sampel 1, 2, 3, dan 6 disebabkan karena adanya kandungan siklamat pada sampel dan pada sampel nomor 4, 5 dan 7 tidak terjadi endapan putih, hal ini menyatakan bahwa sampel tidak mengandung siklamat.

Pada Sampel Nomor 1, 2, 3 dan 6 terjadi banyak pengendapan ini disebabkan karena banyaknya pemakaian siklamat pada minuman es cendol. Sedangkan sampel nomor 4, 5 dan 7 tidak terjadi pengendapan ini disebabkan karena tidak ada pemakaian siklamat pada minuman es cendol. Hal ini mungkin pemanis yang digunakan pemanis alami seperti; gula palem, gula aren, gula buah, gula tebu, gula jagung.

Prinsip identifikasi adanya siklamat dalam sampel yaitu dengan cara pengendapan. Pengendapan dilakukan dengan cara menambahkan Barium klorida dalam suasana asam kemudian ditambah 


\section{Vol. 10 No. 1 Januari - April 2019}

Kalium Nitrit sehingga akan terbentuk endapan Barium sulfat. Penambahan $\mathrm{HCl}$ $10 \%$ dalam sampel berfungsi untuk mengasamkan larutan. Larutan dibuat dalam keadaan asam agar reaksi yang akan terjadi dapat lebih mudah beraksi. Penambahan $\mathrm{BaCl}_{2}$ berfungsi untuk mengendapkan pengotor-pengotor yang ada dalam larutan. Penambahan $\mathrm{KNO}_{2}$ berfungsi untuk memutuskan ikatan sulfat dalam siklamat ${ }^{(9)}$.

Hasil penelitian yang sejenis yang berjudul "Analisis Zat Pemanis Buatan Pada Minuman Jajanan Yang Dijual Di Pasar Tradisional Kota Manado" Tahun 2012 oleh Nurain A. Hadju dengan uji pengendapan menunjukkan bahwa Kandungan Siklamat Pada Minuman Es Doger Di Pasar Manado (positif) ${ }^{(10)}$.

Hasil penelitian yang sejenis yang berjudul "Analisis Zat Pemanis Buatan (Sakarin dan Siklamat) Pada Pangan Jajanan Di SD Kompleks Laringbangi Kota Makasar" Tahun 2014 oleh Zulfikar Thamrin, dkk dengan uji pengendapan menunjukkan bahwa Adanya Kandungan Siklamat Pada Kue Cup dan Es Doger Di SD Kompleks Laringbangi Kota Makasar (positif) .

Hal ini menyatakan bahwa pemakaian siklamat tidak hanya digunakan dalam minuman es cendol tapi pemakaian siklamat juga digunakan dalam pembuatan kue cup dan jamu.

Berdasarkan Peraturan Menteri Kesehatan Tahun Nomor 033 Tahun 2012 pemanis buatan hanya ditujukan untuk produk rendah energi atau bagi penderita diabetes mellitus dan bukan untuk konsumsi umum apalagi untuk anak - anak ${ }^{(8)}$.

Semua senyawa additif atau bahan tambahan pangan tidak akan bisa diproses/dimetabolisme oleh tubuh. Adapun hasil metabolisme siklamat yang menghasilkan senyawa sikloheksilamin bersifat karsinogenik juga tidak akan bisa diproses atau dimetabolisme. Senyawa ini akan tetap utuh sebagai senyawa sikloheksilamin dalam perut dan akan keluar bersama urin dalam bentuk senyawa sikloheksilamin utuh. Senyawa inilah yang mampu menyebabkan kanker pada kandung kemih serta mampu menyebabkan atropi yaitu pengecilan testikular dan kerusakan kromosom.
Namun bagaimanapun juga senyawa sikloheksilamin ini akan keluar, tetap saja senyawa sikloheksilamin akan ada yang tertinggal dan mengendap dalam sistem pencernaan. Semakin banyak pengkonsumsian pangan yang mengandung pemanis buatan yang berupa siklamat ini maka semakin banyak pula senyawa ini akan mengendap dalam sistem pencernaan $^{(9)}$.

\section{KESIMPULAN}

Dari analisa kualitatif pada minuman es cendol yang diperjualbelikan di pinggiran pasar tembung sebanyak 7 Sampel diperoleh hasil sampel nomor 1, 2, 3, 6 positif $(+)$ mengandung siklamat dan sampel nomor 4, 5 dan 7 negatif (-) tidak mengandung siklamat. Menurut hasil yang diperoleh dari analisa kualitatif pada minuman es cendol yang diperjualbelikan di pinggiran pasar tembung seharusnya tidak dikonsumsi oleh anak sekolah maupun masyarakat. Meskipun, pemakaian siklamat diizinkan oleh pemerintah tapi apabila siklamat dikonsumsi secara rutin akan mengakibatkan dampak negatif bagi tubuh

\section{DAFTAR PUSTAKA}

1. Indrati R dan MG. Pendidikan Konsumen Pangan: Aspek Pengolahan dan Keamanan. 1st ed. Jakarta: Kencana; 2014.

2. Reysa E. Rahasia Mengetahui Makanan Berbahaya. Jakarta: Titik Media Publisher; 2013.

3. Wibowoutomo B. Pengembangan Metode Penetapan Kadar Siklamat Kromatografi Kinerja Tinggi Guna Diimplementasu Dalam Kajian Paparan, Teknologi dan Kejuruan. Jakarta: PT. Kalma Media; 2002.

4. Murdiati A dan A. Panduan Penyiapan Pangan Sehat Untuk Semua. 2nd ed. Jakarta: Kencana Prenadamedia Group; 2013.

5. Rohman A. Analisis Makanan. Cetakan 1. Yogyakarta: Gadjah Mada 
University Press; 2007.

6. Yuliarti N. Awas Bahaya Dibalik

Lezatnya Makanan. Yogyakarta: CV. Andi Offset; 2007.

7. Permenkes No.033.Tahun 2012.

Bahan Tambahan Pangan (BTP).pdf.

2012;

8. Cahyadi W. Analisis dan Aspek Kesehatan Bahan Tambahan Pangan.

2nd ed. Jakarta: Bumi Aksara; 2012.

9. Indrie Ambar Sari Ea. Penerapan

Standar Pengguanaan Pemanis Buatan

Pada Produk Pangan. 2011;

10. Nurain A. Hadju. Analisis Zat

Pemanis Buatan Pada Minuman

Jajanan Yang Dijual di Pasar

Tradisional Kota Manado. 2012;

Available from:

ejurnal.unsrat.ac.id/index.php/cocos/ar ticle/viewFile/725/582. 